\title{
DEPENDENCIES OF THE LEAD OF FRONT DRIVING WHEELS ON DIFFERENT TIRE DEFORMATIONS FOR A MFWD TRACTOR
}

\author{
Algirdas Janulevičius, Gediminas Pupinis, Justas Lukštas, \\ Vidas Damanauskas, Vaclovas Kurkauskas \\ Institute of Power and Transport Machinery Engineering, Aleksandras Stulginskis University, \\ Akademija, Kaunas District, Lithuania
}

Submitted 2805 2014; resubmitted 2 October 2014, 26 February 2015; accepted 3 March 2015; first published online 17 July 2015

\begin{abstract}
Tractors are the main machines in agricultural production processes. Agricultural tractors commonly employ a four-wheel drive transmission. To reach maximum efficiency in production works, tractors are loaded by as high thrust as possible. The consequence of it, quite often, is that the slippage of driving wheels grows to the limit that is not allowed. To reduce the slippage, various ways are pointed out in terramechanics. One way is to increase the tractor's weight by adding ballast. The other way is to increase the contact area between tires and the supporting surface. The slippage can be also reduced with traction control and other relevant systems. These methods, which help to reduce slippage, also affect tire deformation. When proportion of tires deformation is not the same as proportion of their sizes, the consequence is change of the lead of front wheels. In this paper analysis is presented, how the lead of front wheels affects the work of MFWD tractor in different conditions. Test results are presented for a MFWD tractor, how the lead of front wheels varies depending on deformation ratios between front and rear tires. For a MFWD tractor, values of deformation ratio between front and rear tires were determined, which ensured effective and which produced unreasonable values of lead of front wheels.
\end{abstract}

Keywords: tractor; front wheels lead; tire pressure; tire deformation; slippage/skid.

\section{Introduction}

Tractors and agricultural machine units are the basic tools used in field production and internal field transport. Agricultural tractors require four-wheel drive, but standard four-by-four systems do not work when front wheels are smaller than rear wheels, as the smaller front wheels would turn faster than the rear wheels. The solution lies with a special four-by-four system known as MFWD. Mechanical front-wheel drive provides four-byfour capabilities to tractors with different-sized front and rear wheels. The use of a four-wheel drive system offers a number of advantages over two-wheel drive, mainly because it improves the tractor's ability to work in soft and wet soil and to cross slippery and uneven terrain (Patterson et al. 2013; Stoilov, Kostadinov 2009; Wong 2009). However, as noted by Molari et al. (2012), Vantsevich (2007) and Żebrowski (2010) under certain circumstances, when the surface of soil is dry and hard, there is a tendency for a MFWD tractors to suffer a reduction of efficiency in power delivery as a result of the interaction between front and rear axles being less than optimal. In order to fully exploit the advantages of four-wheel drive and to avoid premature wear of transmission and tires, the peripheral speed of the front axle must be higher than the rear, on unequal wheel tractors. The front tires on a front wheel assist tractor need to travel between $1-5 \%$ faster than the rear tires. This difference in speed is called lead.

Traction ability of any tractor depends on main factors, namely: engine power, transmission type, tractor weight, contact area of driving tires and the soil strength (Janulevičius, Giedra 2008; Lyasko 2010; Wong 2009). The soil strength determines the traction force generated by tractor driving wheels, the wheel slippage and the rolling resistance on the tractor tires strength (Kichler et al. 2011; Wong 2009). Driving wheel slippage and the rolling resistance are regarded as the main reasons for power losses. When the soil is hard (dry), the grip is good and this results in a greater traction force, lower wheel slippage and rolling resistance (Bris et al. 2011; Taghavifar, Mardani 2013). But when the soil

Corresponding author: Algirdas Janulevičius

E-mail: algirdas.janulevicius@asu.lt 
is soft (wet), the driving wheels slip, resulting in high rolling resistance, which causes power losses and reduction in tractor's draft (Elwaleed et al. 2006; Kichler et al. 2011; Kiss 2003; Taghavifar, Mardani 2013). The research shows that from 20 to $55 \%$ of the total tractor power may be lost in the interaction of tires with the terrain (Elwaleed et al. 2006; Kichler et al. 2011; Šmerda, Čupera 2010). This energy is not simply wasted - part of it produces a soil compaction, which may be detrimental to crop production (Chan et al. 2006; Kichler et al. 2011). This problem of soft soil can be solved and tractor power utilized for thrust more efficiently by increasing tractor's weight and contact area between tires and the terrain. Thus, the MFWD tractor is preferable because its full weight is utilized for pressing on driving wheels, and the contact area between tires and the supporting surface is increased due to more driving wheels in action (Pranav, Pandey 2008; Stoilov, Kostadinov 2009; Taghavifar, Mardani 2013).

Most small and medium duty four wheel drive tractors are available with different sizes of their front and rear wheels. Most such MFWD tractors are manufactured in such a way that in static conditions rear wheels would be loaded by 55 to $65 \%$ of the total weight of the tractor. Tractor researchers recommend maintaining this proportion of vertical wheel loads in working conditions as well (Bris et al. 2011; Stoilov, Kostadinov 2009; Máthé et al. 2013; Żebrowski 2010). If it fails, it is recommended to aim that proportion between vertical loads of front and rear wheels would not deviate more than 10\% (Pranav, Pandey 2008; Wong 2009).

One of the most important operational indicators shows what part of tractor's power is used efficiently for the work. Economic performance indicators of overall tractor/machine assembly depend on engine load and its mode of operation (Janulevičius et al. 2013; Macor, Rossetti 2013; Rahman, Yahya 2013). Aiming at maximum economic efficiency in tillage operations, operators have to use tractors with potentially larger thrust (Kichler et al. 2011; Lyasko 2010; Molari et al. 2012). Traction force depends on the pulling power and running speed. The usual speed of a tractor in field operations ranges from 0.83 to $4.2 \mathrm{~m} / \mathrm{s}$ (Kichler et al. 2011; Sahu, Raheman 2006). In this range of speed driving wheel slippage reaches its maximal value; therefore, the aim should be to reduce tire slippage and use more tractor power for thrust (Pranav, Pandey 2008; Šmerda, Čupera 2010). Terramechanics points out several essential ways how to reduce the slippage. One possibility is to increase tractor's weight by adding ballast. The other possibility is to enlarge the contact area between tires and terrain. The slippage can be also reduced with traction control and other relevant systems. With enlargement of the contact area between tires and terrain tractor tires make less negative effect on the field (Elwaleed et al. 2006; Taghavifar, Mardani 2013) and the result is less compacted soil under the tracks (Arvidsson, Keller 2007; Chan et al. 2006; Kichler et al. 2011; Patel, Mani 2011). Due to enlarged contact area tires sink less into the soil and the track is shallower. Furthermore, due to the larger contact area rolling resistance is smaller in soft soil (Elwaleed et al. 2006). The more tires deform - the larger contact area between tires and the terrain. The contact area between tires and the terrain can be increased by reducing inflation pressure in the tires (Sapragonas, Dargužis 2011; Taghavifar, Mardani 2013; Xia 2011). Based on finite element modeling, Xia (2011) constructed tire/terrain interaction model and provided dependences, how the tire/terrain contact area, rolling radius, traction force, soil compaction and other indicators depend on the tire inflation pressure.

Slippage of driving wheels can be reduced by mounting ballast weights to the tractor. Depending on the place where ballast weights are mounted and weight value, traction force can be increased by up to 15\% (Janulevičius, Giedra 2008; Pranav, Pandey 2008). However, added weight increases the rolling resistance of the tires, so when weights are added, the effect on the rolling resistance should be taken into account (Patterson et al. 2013; Stoilov, Kostadinov 2009; Taghavifar, Mardani 2013). This method also has another very important drawback - a danger always remains to compact the soil too much and damage its deep structure (much deeper than it is tilled), which can reduce soil productivity (Arvidsson, Keller 2007; Pranav, Pandey 2008; Taghavifar, Mardani 2013). As a first measure for reducing slippage, tractor researchers recommend lowering air pressure in the tires (Elwaleed et al. 2006; Kiss 2003; Šmerda, Čupera 2010; Taghavifar, Mardani 2013). Currently, many tractors are operated with inflation pressure in the tires lowered to $80 \mathrm{kPa}$ and even to a lesser value. It means that when the tires deform more, tractor weight is distributed over a larger contact area and the wheels' pressure to the soil decreases. Driving wheels less 'sink' into the soil, tracks are not so deep and the rolling resistance is reduced. Tire inflation pressure is regarded as the important factor which affects the tractor field performance indicators, such as traction force (Elwaleed et al. 2006; Šmerda, Čupera 2010; Wong 2009). However, when the tractor is working with lowered air pressure in the tires, there is always a risk that deformed tires will lose their specified proportions between each other. When specified proportions between tires are lost, wheel kinematic mismatch occurs (Janulevičius et al. 2014; Macor, Rossetti 2013; Stoilov, Kostadinov 2009; Vantsevich 2008; Żebrowski 2010) and the lead of front wheels changes (Molari et al. 2012; Szente 2009). Simulation results of Bris et al. (2011); Xia (2011) show that increasing inflation pressure is an efficient way to increase the tire stiffness and reduce tire vertical deformation.

Modern four-wheel drive tractors often have a rigid drive connection between front and rear wheels. Contrary to the highway vehicles (Patterson et al. 2013; Vantsevich 2008), agricultural tractor drivelines usually do not have any mechanism to compensate variations in effective wheel radiuses that depend on the load, tire elasticity, inflation pressure, tire type or wear (Molari et al. 2012; Szente 2009; Żebrowski 2010). Tire radiuses have to be matched so that the front and rear axle speeds would produce the same ground speed. As the 
front wheels are smaller, they must turn more quickly in comparison to rear wheels to reach approximately the same ground speed for front and rear tires. Added to this speed difference, the front wheels usually are specified to rotate slightly faster than the ideal rotational speed that would give exactly the same ground speed as the rear tires. The transmission is constructed to have a lead ratio $\left(s_{p}\right)$ for the front wheels that is defined by (Molari et al. 2012):

$$
s_{p}=\frac{v_{t}^{f}-v_{t}^{r}}{v_{t}^{r}},
$$

where: $v_{t}^{f}$ and $v_{t}^{r}$ are theoretical speeds of the front and rear wheels respectively.

The front tires of agricultural tractors are generally driven around $2 \%$ faster ( $2 \%$ lead) than the matching speed over the ground of the rears. This makes the tractor easier to steer, but more importantly, more efficient. The front wheels when working in tilled soil, operate more efficiently at higher slippage than the rears, which are tracking in the soil consolidated by the front wheels (Molari et al. 2012; Szente 2009; Żebrowski 2010). This ratio between front and rear axle drives is not standard with all MFWD tractors, which is evidenced by varying tire sizes used. This lead of the front drive wheels varies between tractor models, but usually is in the range from $1.5 \%$ to $3 \%$. Any value of lead of front wheels in the range from $1 \%$ to $5 \%$ is considered acceptable when the tractor is working in soft soil (Szente 2009). Positive lead of front wheels should never be less than $1 \%$ and never higher than $5 \%$, otherwise the tires will become deformed or suffer excessive wear (Żebrowski 2010). Values of lead of front wheels out of this range could cause problems with handling and instability (lead $<1$, the rear axle 'pushes' the tractor in respect to the front axle) or cause excessive lead between the front and rear tires (lead $>5$, excessive mechanic effort of all the transmission chain). In both the cases, the tires are subject to rapid and uneven wear (Szente 2009).

When MFWD tractor is operating with the incorrect value of lead, the tractor will often bounce and vibrate as the front and rear tires slip relative to each other to make up for speed differences. This is usually most noticeable on hard and dry surfaces (Szente 2009; Żebrowski 2010). It can be difficult to tell the cause of this without careful measurement. If the percentage of lead of front wheels is too low, the front wheels will not be doing their fair share of work. This can be detected during thrust operation (particularly in soft conditions) by switching to two wheel drive mode. If wheel slip does not increase noticeably after switching into two wheel drive mode, this indicates that the lead of front wheels is too low. If the lead of front wheels is too low or sub-zero, the rear wheels are trying to push the front wheels and power circulation will occur in the transmission. This can result in transmission damage, excessive wear of tires, rough ride, increased turning radius and excessive use of fuel (Janulevičius et al. 2014; Vantsevich 2007; Żebrowski 2010). This circulating power not only increases wear of tires and driveline components, but also reduces the overall efficiency of the tractor. This circulating power, which is exchanged between the axles, is subject to losses in various places: between the front wheels and the terrain, between the ground and the rear wheels, and within the transmission itself. Thus, the tractor needs more power to compensate for these re-circulation losses. If the value of lead of front wheels is too high, front axle may bounce, front tires may wear rapidly and the soil may be messed under the front tires. This is mostly noticeable on hard terrain (Wong 2009; Żebrowski 2010).

The analysis shows that in order to improve the efficiency of the tractor (more thrust, less slippage, lower fuel consumption, less impact on soil, etc.), tire deformations are inevitable, and the result is change in the lead of front wheels for MFWD tractor.

Purpose of the study: to determine the dependence, how the lead of front wheels varies depending on deformation ratios between front and rear tires for a MFWD tractor.

\section{Materials and Methods}

When tractor tires are deformed, wheel radiuses and theoretical rolling speeds are changed. Tire deformation depends on the vertical wheel loads, soil strength, tire dimensions and inflation pressures in the tires. When front and rear tires deform in such a way that proportion between wheel radiuses is changed, theoretical wheel speeds become different. Although theoretical speeds of the wheels vary, they are forced to move at the same ground speed, which is equal to the speed of the tractor - this is because axles are rigidly connected to the tractor's drive mechanism. While theoretical speeds are different, the actual ground speed must be equal, so one pair of driving wheels will be slipping, and the other skidding (slippage means that tractor wheels are shifting against the direction of motion, and skid means that tractor wheels are shifting in the same direction as the tractor moves). We can record the following equation for inter-relation between speeds:

$$
v=v_{t}^{r}\left(1-\left( \pm \delta^{r}\right)\right)=v_{t}^{f}\left(1-\left( \pm \delta^{f}\right)\right),
$$

where: $v$ is the actual speed of the tractor as well as its front and rear wheels; $v_{t}^{f}$ and $v_{t}^{r}$ are theoretical speeds of front and rear wheels; $\delta^{f}$ and $\delta^{r}$ are slippage/skid coefficients of front and rear driving wheels (' $+\delta$ ' - when the driving wheels are slipping, and ' $-\delta$ ' - when the driving wheels are skidding).

By admitting that theoretical speed of a wheel is equal to its dynamic radius multiplied by its angular velocity, we can rewrite Eq. (2) as follows:

$$
\left.\omega^{r} r_{d}^{r}\left(1- \pm \delta^{r}\right)\right)=\omega^{f} r_{d}^{f}\left(1-\left( \pm \delta^{f}\right)\right) .
$$

where: $\omega^{f}$ and $\omega^{r}$ are angular velocity of the front and rear wheels; $r_{d}^{f}$ and $r_{d}^{r}$ are dynamic radiuses of front and rear wheels. The dynamic radius is obtained from the driving torque and the tractive force, which is generated in the tire-terrain interface. When the tractor 
moves with uniform speed, the angular acceleration of the driving wheel is zero. In this case, the dynamic radius is defined as the distance between the centre of the wheel and the resultant of the elementary tractive forces generated in the tire-terrain interface (Kiss 2003; Szente 2009).

Slippage $\delta$ is defined as follows (Battiato, Diserens 2013; Maclaurin 2014; Wong 2009):

$$
\begin{aligned}
& \delta=\frac{\omega r_{d}-v}{\omega r_{d}}, \text { or } \\
& \delta=\frac{v_{t}-v}{v_{t}},
\end{aligned}
$$

where: $v_{t}$ is the theoretical velocity of the wheel; $v$ is the actual forward velocity of the axle of the wheel; $\omega$ is the angular velocity of the wheel

From the Eq. (3) we can see that MFWD tractor will not be submitted to slippage of wheels when ratio between deformations of rear and front wheel tires is equal to the ratio between angular speeds of rear and front wheels:

$$
\frac{\Delta r_{d}^{r}}{\Delta r_{d}^{f}}=\frac{\omega^{f}}{\omega^{r}},
$$

where: $\Delta r_{d}^{f}$ and $\Delta r_{d}^{r}$ are deformations of front and rear wheel tires.

\subsection{Equipment, Site and Layout}

To determine dependencies between front/rear tire deformation ratios and the lead of front wheels for a MFWD tractor, a new tractor Valtra T-213 VERSU was used that not yet had been in service. For the research, different tire deformation values were obtained by changing inflation pressures in the tires and the ballasting of the tractor. Specifications of the tractor used for the research are listed in Table 1.

Tests were conducted on a flat hard surface, on a straight path. The stretch selected road for the test $120 \mathrm{~m}$ long (Fig. 1). The main $80 \mathrm{~m}$ distance was used for test, i.e. to determine the travel distance of the front and the rear wheels over 10 wheels-turnings. The $30 \mathrm{~m}$ distance was used for acceleration and $10 \mathrm{~m}$ distance - for preparation the tractor (to change configuration). Tests were carried out with all possible combinations of pressures (namely, 65, 110, 155, 200, $245 \mathrm{kPa}$ ) for the front/rear tires of the tractor (25 combinations in total).

All tests were performed both with enabled and disabled front axle, by traveling the same stretch in the same direction. During the tests, the drive axle differential was locked. During all the tests, ground speed was $1.43 \mathrm{~m} / \mathrm{s}$; engine speed was $1500 \mathrm{rpm}$. It was assumed that when the tractor (not loaded by traction force) was driving with disabled front axle at a constant speed

Table 1. Tractor (Valta T-213 VERSU) specifications

\begin{tabular}{ll}
\hline Engine (AGCO Power 74 AWI-4V): & \\
Engine type & 6 cylinder, liquid-cooled, in-line, turbocharged, DI \\
Rated power & $156 \mathrm{~kW}$ at $2200 \mathrm{rpm}$ \\
Maximum power & $165 \mathrm{~kW}$ at $1900 \mathrm{rpm}$ \\
Maximum torque & $950 \mathrm{Nm}$ at $1500 \mathrm{rpm}$ \\
\hline Transmission and Chassis: & MFWD \\
Drive type & Gear, five power shift gears in two gears and three ranges \\
Transmission type & 30 \\
Forward gear & 30 \\
Reverse gear & Wet multi-disc \\
Clutch & $540 / 65 \mathrm{R} 30(143 \mathrm{D})$ MICHELIN MULTIBIB \\
Tires: front & $650 / 65 \mathrm{R} 42(158 \mathrm{D})$ MICHELIN MULTIBIB \\
$\quad$ rear & $2.748 \mathrm{~m}$ \\
Wheelbase & hydrostatic power \\
Steering & hydraulic wet disc \\
Brakes & $7420 \mathrm{~kg}$ \\
\hline Tractor mass (operating) & $55 \%$ (rear axle), $45 \%$ (front axle) \\
Weight distribution & closed center pressure flow compensating (pressure: 200 bar) \\
\hline Hydraulics &
\end{tabular}

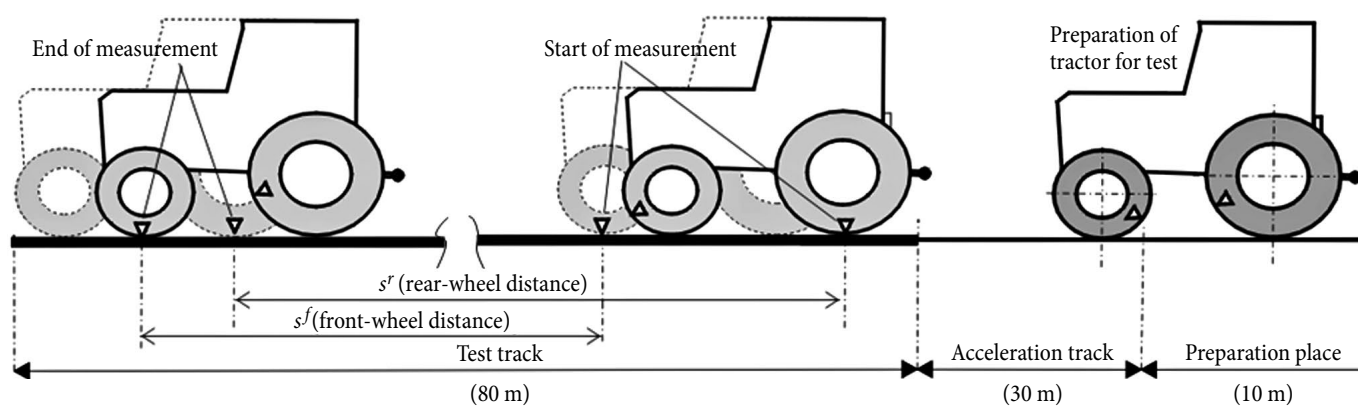

Fig. 1. Testing scheme 
(i.e., the tractor was already accelerated), front and rear wheels were rolling without slippage/skid. When front axle was enabled, driving wheels were slipping/skidding because of kinematic mismatch. During the tests, the distances were measured, how far each of the front and rear wheels traveled during 10 revolutions - with front axle enabled and disabled. Markers were attached to the front and rear wheels and marks were made on the road for the distances that both front and rear wheel pairs traveled by turning 10 revolutions (Fig. 1). To measure the distance, laser gauge Bosch PLR 50 was used, having a measurement error of $\pm 2 \mathrm{~mm}$. For each combination of inflation pressures both with enabled and disabled front axle, three runs were performed to ensure repeatability and the reliability of the obtained results. Test results represent arithmetic average of all repetitions.

Vertical load of each tractor wheel was determined by electronic axis scales WPD-2, specified for weight range from 5 to $15000 \mathrm{~kg}$ with $1 \mathrm{~kg}$ error.

\subsection{Calculations}

Percent of slippage (or skid - when the result was obtained with a minus sign) of tractor's front and rear wheels was calculated according to the following equations:

$$
\begin{aligned}
& \delta^{f}=\frac{s_{t}^{f}-s_{a}^{f}}{s_{t}^{f}} 100[\%] ; \\
& \delta^{r}=\frac{s_{t}^{r}-s_{a}^{r}}{s_{t}^{r}} 100[\%],
\end{aligned}
$$

where: $s_{t}^{f}$ and $s_{t}^{r}$ are the theoretical distances of front and rear wheels' travel during 10 revolutions accordingly (front axle is disabled); $s_{a}^{f}$ and $s_{a}^{r}$ are the actual distances of front and rear wheels' travel during 10 revolutions in four wheels drive condition. The theoretical distances $s_{t}^{f}$ and $s_{t}^{r}$ was determined according to American Society of Agricultural Engineers - ASAE Standard S296.2. as the distance travelled per revolution of the wheel when operating at the specified zero condition.

Deformation coefficient for vehicle's tires is calculated according to the following equation:

$$
\Delta r=\frac{r_{d}-r_{0}}{H},
$$

where: $r_{d}$ is the dynamic radius of tire; $r_{0}$ is the inner radius of tire; $H$ is the height of tire.

The tire dynamic radius $r_{d}$ was determined according to ASAE Standard S296.2. as the distance travelled per revolution of the wheel divided by $2 \pi$ when operating at the specified zero condition. The latter was here assumed to be the tractor operating at zero drawbar pull on a smooth road. Zoz, Grisso (2003), Battiato, Diserens (2013) show that, the difference in measured dynamic radii between a hard road and a test surface is small under normal agricultural soil conditions (untilled soil), and thus has little impact on the final results.

Deformation coefficients for tractor's front and rear wheel tires were calculated according to the following equations:

$$
\begin{aligned}
& \Delta r_{d}^{f}=\frac{s_{4 \times 2}^{f}-10 \pi d_{0}^{f}}{20 \pi H^{f}} ; \\
& \Delta r_{d}^{r}=\frac{s_{4 \times 2}^{r}-10 \pi d_{0}^{r}}{20 \pi H^{r}},
\end{aligned}
$$

where: $d_{0}^{f}$ and $d_{0}^{r}-$ inner diameters of front and rear wheel tires respectively; $H^{f}$ and $H^{r}$ - height of front and rear wheel tires respectively; $\pi$ - mathematical constant $(\pi \approx 3.14)$.

Percentage of the lead for the front axle was calculated according to the following equation:

$$
s_{p}=\frac{\delta^{f}-\delta^{r}}{1-\delta^{f}} 100[\%] .
$$

The latter equation is obtained by inserting mathematical expressions from the second equation (theoretical speeds of the front and rear wheels) into the first equation.

\section{Results and Discussion}

In these tests, different tire deformation values were obtained by changing inflation pressures in the tires. Brand new tractor with brand new tires was used for the tests. Fig. 2 shows tire deformation dependences on tire inflation pressure for the tractor not loaded by traction force and traveling at the speed of $1.39 \mathrm{~m} / \mathrm{s}$. Coefficient $\Delta r$ shows tire deformation extent. When a tire is not deformed, this coefficient is equal to one.

Fig. 2 shows that when inflation pressures in front and rear tires were identical, rear tires of the tractor deformed slightly more than the front tires. Such difference in tire deformation can be related to differences in tire sizes and their vertical load ratios. Similar patterns in tire rolling radiuses' variation depending on tire inflation pressure were obtained by Xia (2011), who created tire/terrain interaction model on the basis of finite element modeling. Fig. 2 shows that air pressure has a significant impact on tire deformation. When tire pressures were lowered from 245 to $65 \mathrm{kPa}$, tire deforma-

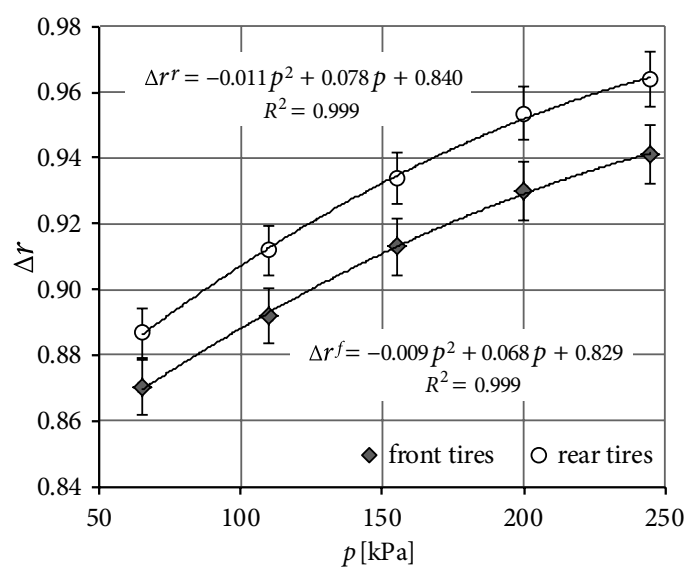

Fig. 2. Front and rear wheel tires deformation coefficient dependences on air pressure in the tires for the tractor driving at a speed of $1.43 \mathrm{~m} / \mathrm{s}$ 
tion coefficient values decreased by $0.07 \div 0.08$. Namely, for the front tires this coefficient decreased by 0.078 , i.e. from 0.963 to 0.885 . In addition, for the rear tires this coefficient decreased by 0.072 , i.e., from 0.94 to 0.868 . It may be noted that by creating different air pressures in the front and rear tires; we can obtain their uniform deformations, i.e., deformations with equal deformation coefficients.

Figs 3 and 4 show, respectively, rear and front tire deformation dependences on inflation pressures in them, when tractor is running at the speed of $1.43 \mathrm{~m} / \mathrm{s}$ without ballast mass and with $650 \mathrm{~kg}$ ballast mass on the rear hydraulic lift. From these figures, it is noticeable that tire inflation pressures and tire vertical loads have impact on the deformations. When $650 \mathrm{~kg}$ ballast mass was attached to the rear hydraulic lift, deformation coefficient for the rear tires increased, and for the front tires decreased in the range of $0.02-0.05$. It is obvious that front and rear tire deformations due to the ballast mass affected the lead value for the front wheels of MFWD tractor.

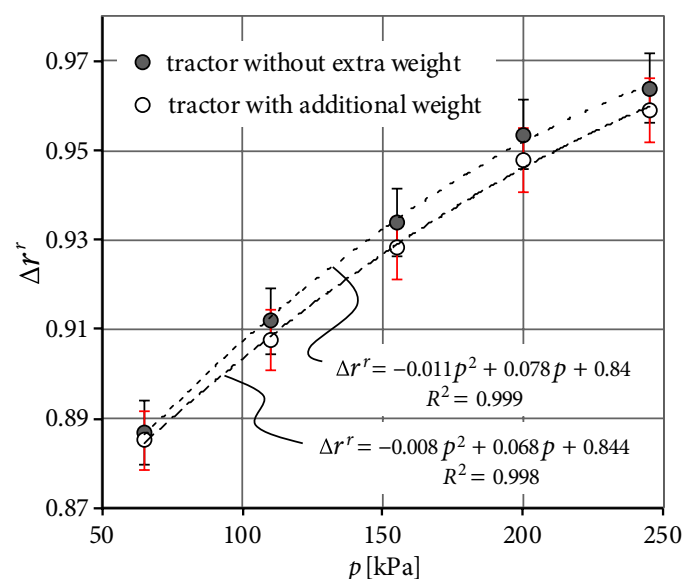

Fig. 3. Rear wheel tire deformation coefficient dependences on air pressure in the tires when tractor is moving at a speed of $1.43 \mathrm{~m} / \mathrm{s}$ without ballast weights and with $650 \mathrm{~kg}$ ballast mass on the rear hydraulic lift

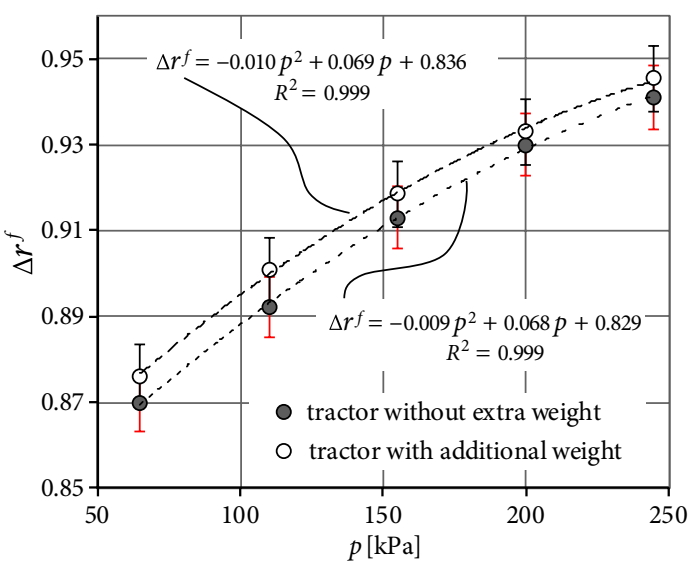

Fig. 4. Front wheel tire deformation coefficient dependences on air pressure in the tires when tractor is moving at a speed of $1.43 \mathrm{~m} / \mathrm{s}$ without ballast weights and with $650 \mathrm{~kg}$ ballast mass on the rear hydraulic lift
Any tire deformation depends on many parameters, including vertical wheel load, tire dimensions, inflation pressure in the tire, etc., so every tire deformation case is individual. Disproportionate tire deformation makes kinematic mismatch of MFWD tractor wheels and changes the lead value of front wheels. In case of kinematic mismatch between driving wheels of MFWD tractor, one pair of driving wheels is forced to slippage, and the other - skid (Janulevičius et al. 2014; Stoilov, Kostadinov 2009; Żebrowski 2010). In the rest of this paper analysis is presented, how tire deformation affects driving wheels' slippage/skid and the lead value of front wheels for a MFWD tractor.

Figs 5 and 6 correspondingly show how slippage/skid of rear and front wheels depend on the tire deformation values. Fig. 5 illustrates that driving rear wheels of the MFWD tractor can roll without slippage/ skid when front and rear tires during motion deform proportionately to their sizes, i.e., when front and rear tire deformation coefficients are more or less the same. Similarly, Fig. 6 illustrates that driving front wheels of the MFWD tractor can roll without slippage/skid when front and rear tires during motion deform proportionately to their sizes. It follows that driving wheels of both axles of the MFWD tractor can roll without slippage/ skid when front and rear tire deformation coefficients are more or less the same. Such cases are acceptable when tractor works at higher speeds on hard surface roads (e.g. in the transport works).

When deformation coefficient of the rear driving wheel tires was higher than deformation coefficient of the front driving wheel tires, rear wheels were slipping, and the front wheels - skidding. The maximum slippage of rear driving wheels $(2.29 \%)$ and skid of front driving wheels $(1.96 \%)$ occurred when tire deformation coefficients were as follows: for the rear tires -0.97 , for the front tires - 0.87. Sources of information (Szente 2009; Wong 2009) state that when rear wheels of MFWD tractor are slipping more than the front ones, the case is not satisfactory, because the tractor fails to utilize its maximum potential of thrust.

When working in field, the preferable case was obtained when deformation coefficient of the rear driving wheel tires was lower than deformation coefficient of the front driving wheel tires - in this case rear wheels were skidding, and the front wheels - slipping. The maximum slippage of front driving wheels $(2.42 \%)$ and skid of rear driving wheels $(1.26 \%)$ occurred when tire deformation coefficients were as follows: for the rear tires -0.89 , for the front tires -0.95 . In this case, in the field conditions, both front and rear wheels would slippage if the tractor was loaded by draft. Depending on the value of lead, front wheels would slippage more.

Fig. 7 illustrates how the lead of front driving wheels depends on deformation values of front and rear tires for a MFWD tractor. Fig. 7 illustrates that when front and rear tire deformations for the tested tractor were more or less identical, i.e., when their deformation coefficient values were identical, the lead of front driving wheels was close to zero. When deformation coefficient value of the rear driving wheels was lower than defor- 


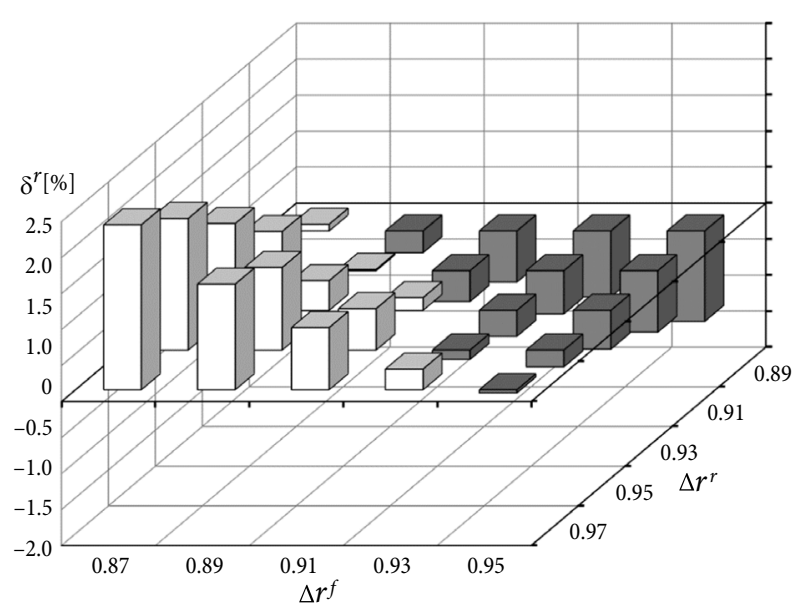

Fig. 5. Rear wheel slippage/skid dependences on deformation values of front and rear tires

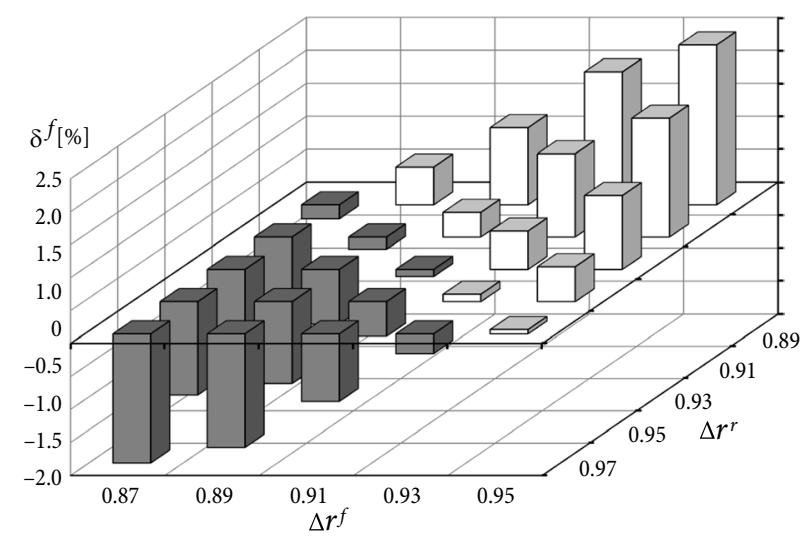

Fig. 6. Front wheel slippage/skid dependences on deformation values of front and rear tires

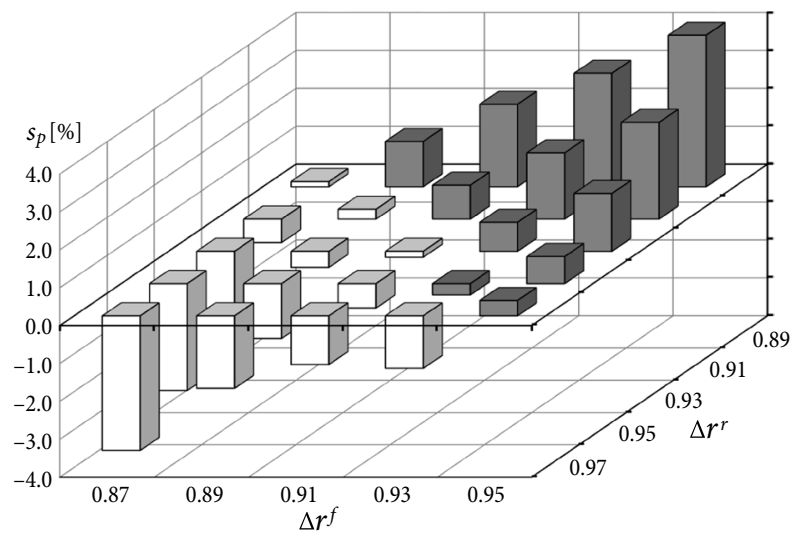

Fig. 7. Dependences of the lead of front driving wheels on deformation values of front and rear tires

mation coefficient value of the front driving wheels, the lead of front driving wheels for the MFWD tractor was greater than zero (positive).

The largest lead of front driving wheels (4\%) occurred when tire deformation coefficient values were as follows: for the rear tires -0.89 , for the front tires 0.95 . When deformation coefficient value of the rear driving wheels was higher than deformation coefficient value of the front driving wheels, the lead of front driving wheels for the MFWD tractor was lower than zero (negative). The largest negative lead of front driving wheels $(-3.55 \%)$ occurred when tire deformation coefficient values were as follows: for the rear tires -0.97 , for the front tires -0.87 . The effective lead of front driving wheels for the MFWD tractors, depending on the operating conditions, prevails in the range of $1.5-4.0 \%$. When working at higher speeds, rational lead of front driving wheels on a hard surface usually is in the range of 1-1.5\% (Molari et al. 2012; Szente 2009). For MFWD tractor working in the kneaded soil and loaded by traction force, rational lead of front driving wheels is in the range of 3-4\% (Szente 2009; Żebrowski 2010). From test results presented in Fig. 6 we can see that the lead of front driving wheels is in the range from 1 to $1.5 \%$ when deformation coefficient of rear tires is lower than deformation coefficient of front tires by $0.02-0.04$. The lead of front driving wheels is obtained in the range from 3 to $4 \%$ when deformation coefficient of rear tires is lower than deformation coefficient of front tires by $0.05-0.08$.

When front tires of MFWD tractor were deformed more than the rear tires, i.e., when deformation coefficient of the rear driving wheel tires was higher than deformation coefficient of the front driving wheel tires, the lead of front driving wheels was very small or subzero (negative). Information sources (Molari et al. 2012; Szente 2009; Wong 2009) conclude that the work of MFWD tractor is not effective when the lead of front driving wheels is too low or negative. If percentage of lead of front driving wheels is too low, the front wheels will not be doing their fair share of work. If the lead is sub-zero, the rear wheels are trying to push the front wheels and power circulation will occur in the transmission. This can result in excessive tires wear and increased fuel consumption (Molari et al. 2012; Szente 2009; Wong 2009; Żebrowski 2010).

The results of this study may provide helpful practical purpose insights into a reasonable choice of tractor tires pressure as well as effective control of driving wheels slip, with a view to optimizing lead of front driving wheels, thereby reducing the costs of operation process (fuel consumption, tire wear, etc.). The front and rear tire pressure difference depending on the tire load. When working in the field, the preferable case was obtained when deformation coefficient of the rear driving wheel tires was lower (0.01-0.06) than deformation coefficient of the front driving wheel tires. In this case, both front and rear wheels slip if the tractor would be loaded by traction force. Depending on the value of lead, front wheels would slip more.

The analysis shows that in order to improve the efficiency of the tractor (more thrust, less slippage, lower fuel consumption, etc.), tire pressure variety is inevitable, and the result is change in the lead. Meanwhile, many researchers in their works solve the problem of tractor slippage normalization by reducing the tire pressures or adding ballast masses. However, the influence of variations in tire pressures on lead of front driving wheels is considered just moderately. The analysis of front driving wheels lead is innovation of this paper. 


\section{Conclusions}

Any value of lead of the front wheels in the range from 1.5 to $5 \%$ is considered acceptable when MFWD tractor is working in soft soil. For the tractor Valta T-213 VERSU with front tires 540/65 R 30 (143 D) MICHELIN MULTIBIB and rear tires 650/65 R 42 (158 D) MICHELIN MULTIBIB the lead of front driving wheels was obtained in the range of $1.5-4.0 \%$ when deformation coefficient of rear driving wheel tires was lower than deformation coefficient of front driving wheel tires by $0.04 \div 0.08$.

Any value of lead of the front wheels in the range from 1 to $1.5 \%$ is considered acceptable when MFWD tractor is working on hard surfaces. For the tractor Valta T-213 VERSU with front tires 540/65 R 30 (143 D) MICHELIN MULTIBIB and rear tires 650/65 R 42 (158 D) MICHELIN MULTIBIB the lead of front driving wheels was obtained in the range of $1.0-1.5 \%$ when deformation coefficient of rear driving wheel tires was lower than deformation coefficient of front driving wheel tires by 0.02-0.04.

If the lead of front wheels is too low or sub-zero, the rear wheels are trying to push the front wheels and power circulation will occur in the transmission. This can result in excessive tires wear and increased fuel consumption. For the tractor Valta T-213 VERSU with front tires 540/65 R 30 (143 D) MICHELIN MULTIBIB and rear tires 650/65 R 42 (158 D) MICHELIN MULTIBIB the lead of front driving wheels was obtained in the range of $0-(-3.55) \%$ when deformation coefficient of rear driving wheel tires was higher than deformation coefficient of front driving wheel tires by $0 \div 0.08$.

\section{References}

ASAE Standard S296.2. Uniform terminology for traction of Agricultural Tractors, Self-Propelled Implements, and other Traction and Transport Devices. American Society of Agricultural Engineers (ASAE).

Arvidsson, J.; Keller, T. 2007. Soil stress as affected by wheel load and tyre inflation pressure, Soil and Tillage Research 96(1-2): 284-291.

http://dx.doi.org/10.1016/j.still.2007.06.012

Battiato, A.; Diserens, E. 2013. Influence of tyre inflation pressure and wheel load on the traction performance of a $65 \mathrm{~kW}$ MFWD tractor on a cohesive soil, Journal of Agricultural Science 5(8): 197-215.

http://dx.doi.org/10.5539/jas.v5n8p197

Bris, S.-S.; Ungureanu, N.; Maican, E.; Murad, E.; Vladut, V. 2011. FEM model to study the influence of tire pressure on agricultural tractor wheel deformations, in Proceedings of 10th International Conference 'Engineering for Rural Development', 26-27 May 2011, Jelgava, Latvia, 223-228.

Chan, K. Y.; Oates, A.; Swan, A. D.; Hayes, R, C.; Dear, B. S.; Peoples, M. B. 2006. Agronomic consequences of tractor wheel compaction on a clay soil, Soil and Tillage Research 89(1): 13-21. http://dx.doi.org/10.1016/j.still.2005.06.007

Elwaleed, A. K.; Yahya, A.; Zohadie, M.; Ahmad, D.; Kheiralla, A. F. 2006. Effect of inflation pressure on motion resistance ratio of a high-lug agricultural tyre, Journal of Terramechanics 43(2): 69-84.

http://dx.doi.org/10.1016/j.jterra.2004.08.006
Janulevičius, A.; Giedra, K. 2008. Tractor ballasting in field work, Mechanika (5): 27-34.

Janulevičius, A.; Juostas, A.; Pupinis, G. 2013. Tractor's engine performance and emission characteristics in the process of ploughing, Energy Conversion and Management 75: 498508. http://dx.doi.org/10.1016/j.enconman.2013.06.052

Janulevičius, A.; Pupinis, G.; Kurkauskas, V. 2014. How driving wheels of front-loaded tractor interact with the terrain depending on tire pressures, Journal of Terramechanics 53: 83-92. http://dx.doi.org/10.1016/j.jterra.2014.03.008

Kichler, C. M.; Fulton, J. P.; Raper, R. L.; McDonald, T. P.; Zech, W. C. 2011. Effects of transmission gear selection on tractor performance and fuel costs during deep tillage operations, Soil and Tillage Research 113(2): 105-111. http://dx.doi.org/10.1016/j.still.2011.03.002

Kiss, P. 2003. Rolling radii of a pneumatic tyre on deformable soil, Biosystems Engineering 85(2): 153-161. http://dx.doi.org/10.1016/S1537-5110(03)00043-6

Lyasko, M. I. 2010. How to calculate the effect of soil conditions on tractive performance, Journal of Terramechanics 47(6): 423-445. http://dx.doi.org/10.1016/j.jterra.2010.04.003

Maclaurin, B. 2014. Using a modified version of the magic formula to describe the traction/slip relationships of tyres in soft cohesive soils, Journal of Terramechanics 52: 1-7. http://dx.doi.org/10.1016/j.jterra.2013.11.005

Macor, A.; Rossetti, A. 2013. Fuel consumption reduction in urban buses by using power split transmissions, Energy Conversion and Management 71: 159-171. http://dx.doi.org/10.1016/j.enconman.2013.03.019

Máthé, L.; Kiss, P.; Laib, L.; Pillinger, G. 2013. Computation of run-off-road vehicle speed from terrain tracks in forensic investigations, Journal of Terramechanics 50(1): 17-27. http://dx.doi.org/10.1016/j.jterra.2012.08.002

Molari, G.; Bellentani, L.; Guarnieri, A.; Walker, M.; Sedoni, E. 2012. Performance of an agricultural tractor fitted with rubber tracks, Biosystems Engineering 111(1): 57-63. http://dx.doi.org/10.1016/j.biosystemseng.2011.10.008

Patel, S. K.; Mani, I. 2011. Effect of multiple passes of tractor with varying normal load on subsoil compaction, Journal of Terramechanics 48(4): 277-284.

http://dx.doi.org/10.1016/j.jterra.2011.06.002

Patterson, M. S.; Gray, J. P.; Bortolin, G.; Vantsevich, V. V. 2013. Fusion of driving and braking tire operational modes and analysis of traction dynamics and energy efficiency of a $4 \times 4$ loader, Journal of Terramechanics 50(2): 133-152. http://dx.doi.org/10.1016/j.jterra.2013.01.003

Pranav, P. K.; Pandey, K. P. 2008. Computer simulation of ballast management for agricultural tractors, Journal of Terramechanics 45(6): 185-192. http://dx.doi.org/10.1016/j.jterra.2008.12.002

Rahman, A.; Yahya, A. 2013. Performance investigation of an advanced tracked prime mover on the low bearing soil, Journal of Terramechanics 50(4): 233-244. http://dx.doi.org/10.1016/j.jterra.2013.06.001

Sahu, R. K.; Raheman, H. 2006. Draught prediction of agricultural implements using reference tillage tools in sandy clay loam soil, Biosystems Engineering 94(2): 275-284. http://dx.doi.org/10.1016/j.biosystemseng.2006.01.015

Sapragonas, J.; Dargužis, A. 2011. Model of radial deformations of protector of vehicle tire, Mechanika 17(1): 21-29. http://dx.doi.org/10.5755/j01.mech.17.1.199

Stoilov, S.; Kostadinov, G. D. 2009. Effect of weight distribution on the slip efficiency of a four-wheel-drive skidder, Biosystems Engineering 104(4): 486-492. http://dx.doi.org/10.1016/j.biosystemseng.2009.08.011 
Szente, M. 2009. Slip calculation and analysis for four-wheel drive tractors, Progress in Agricultural Engineering Sciences: A Journal of Agricultural, Environmental and Process Engineering 5: 7-31.

http://dx.doi.org/10.1556/Progress.1.2005.1.2

Šmerda, T.; Čupera, J. 2010. Tire inflation and its influence on drawbar characteristics and performance - energetic indicators of a tractor set, Journal of Terramechanics 47(6): 395-400. http://dx.doi.org/10.1016/j.jterra.2010.02.005

Taghavifar, H.; Mardani, A. 2013. Investigating the effect of velocity, inflation pressure, and vertical load on rolling resistance of a radial ply tire, Journal of Terramechanics 50(2): 99-106. http://dx.doi.org/10.1016/j.jterra.2013.01.005

Vantsevich, V. V. 2007. Multi-wheel drive vehicle energy/fuel efficiency and traction performance: objective function analysis, Journal of Terramechanics 44(3): 239-253. http://dx.doi.org/10.1016/j.jterra.2007.03.003

Vantsevich, V. V. 2008. Power losses and energy efficiency of multi-wheel drive vehicles: a method for evaluation, Journal of Terramechanics 45(3): 89-101. http://dx.doi.org/10.1016/j.jterra.2008.08.001

Wong, J. Y. 2009. Terramechanics and Off-Road Vehicle Engineering: Terrain Behaviour, Off-Road Vehicle Performance and Design. 2nd edition. Butterworth-Heinemann. 488 p.

Xia, K. 2011. Finite element modeling of tire/terrain interaction: Application to predicting soil compaction and tire mobility, Journal of Terramechanics 48(2): 113-123. http://dx.doi.org/10.1016/j.jterra.2010.05.001

Zoz, F. M.; Grisso, R. D. 2003. Traction and Tractor Performance. Tractor design No. 27. ASAE Publication Number 913C0403. American Society of Agricultural Engineers (ASAE). $48 \mathrm{p}$.

Żebrowski, J. 2010. Traction efficiency of a wheeled tractor in construction operations, Automation in Construction 19(2): 100-108. http://dx.doi.org/10.1016/j.autcon.2009.09.007 